\title{
Cinnamomum camphora Leaves Alleviate Allergic Skin Inflammatory Responses In Vitro and In Vivo
}

\author{
Na-Jin Kang, Sang-Chul Han, Seok-Hyun Yoon, Jae-Yeop Sim, Young Hee Maeng, \\ Hee-Kyoung Kang and Eun-Sook Yoo \\ Department of Medicine, School of Medicine, Jeju National University, Jeju, Korea
}

\begin{abstract}
In this study, we investigated the therapeutic potential of Cinnamomum camphora leaves on allergic skin inflammation such as atopic dermatitis. We evaluated the effects of $C$. camphora leaves on human adult low-calcium high-temperature keratinocytes and atopic dermatitis mice. C. camphora leaves inhibited Macrophage-derived chemokine (an inflammatory chemokine) production in interferon- $\gamma(10 \mathrm{ng} / \mathrm{mL})$ stimulated Human adult low-calcium high-temperature keratinocytes in a dose dependent manner. C. camphora leaves suppressed the phosphorylation of janus kinase signal transducer and activator of transcription 1. C. camphora leaves also suppressed the phosphorylation of extracellular signal-regulated kinase $1 / 2$, a central signaling molecule in the inflammation process. These results suggest that $C$. camphora leaves exhibits anti-inflammatory effect via the phosphorylation of signal transducer and activator of transcription 1 and extracellular signal-regulated kinase $1 / 2$. To study the advanced effects of $C$. camphora leaves on atopic dermatitis, we induced experimental atopic dermatitis in mice by applying 2,4-dinitrochlorobenzene. The group treated with $C$. camphora leaves $(100 \mathrm{mg} / \mathrm{kg})$ showed remarkable improvement of atopic dermatitis symptoms: reduced serum immunoglobulin $E$ levels, smaller lymph nodes with reduced thickness and length, decreased ear edema, and reduced levels of inflammatory cell infiltration in the ears. Interestingly, the effects of $C$. camphora leaves on atopic dermatitis symptoms were stronger than those of hydrocort cream, a positive control. Taken together, $C$. camphora leaves showed alleviating effects on the inflammatory chemokine production in vitro and atopic dermatitis symptoms in vivo. These results suggest that $C$. camphora leaves help in the treatment of allergic inflammation such as atopic dermatitis.
\end{abstract}

Key words: Atopic dermatitis, Cinnamomum camphora, 2,4-Dinitrochlorobenzene, Inflammation, Immunoglobulin E, Signal transducer and activator of transcription 1

\section{INTRODUCTION}

Allergic skin inflammation such as atopic dermatitis (AD) is characterized by skin barrier dysfunction, edema, and infiltration of various types of inflammatory cells. AD is a chronic skin disease associated with skin hyper-reactivity, including edema and itching, which affects approximately $10-20 \%$ of children and $1-3 \%$ of adults worldwide (1). This systemic disorder is characterized by thickening of the papillary dermis, parakeratosis, skin barrier dys- function, epidermal hyperplasia, severe skin dehydration, and T-cell hyper-proliferation. The skin lesions in AD patients are characterized by the proliferation and infiltration of various inflammatory cells, mainly eosinophils, mast cells, basophils, and T cells (2,3). Mast cells play an important role in the inflammatory process and anaphylactic reactions. Immunoglobulin (Ig) $\mathrm{E}$ is a crucial therapeutic target for $\mathrm{AD}$, as it is the major activator of mast cells, which release histamine, tryptase, and cytokine (4).

Chemokine is a group of factors that control the activity
Correspondence to: Eun-Sook Yoo, Department of Medicine, School of Medicine, Jeju National University, Jeju 63243, Korea E-mail: eunsyoo@jejunu.ac.kr

Abbreviations used: AD, Atopic dermatitis; DNCB, 2,4-Dinitrochlorobenzene; IgE, Immunoglobulin E; STAT, Signal transducer and activator of transcription 1 .
This is an Open-Access article distributed under the terms of the Creative Commons Attribution Non-Commercial License (http:// creativecommons.org/licenses/by-nc/3.0) which permits unrestricted non-commercial use, distribution, and reproduction in any medium, provided the original work is properly cited. 
of white blood cells, and serve to control the infiltration of inflammatory cells (5). It is closely related to various pathological processes, such as inflammation, allergy, and infectious diseases. Furthermore, chemokine is also known to be involved in the generation and maturation of immune cells, and differentiation of $\mathrm{T}$ cells $(5,6)$. Macrophagederived chemokine (MDC/CCL22) is a typical inflammatory chemokine and a ligand for $\mathrm{CC}$ chemokine receptor 4 (CCR4), which is predominantly expressed on Th2 lymphocytes, basophils and natural killer cells $(7,8)$. Previous studies showed that the MDC level is elevated in the serum and skin lesions of patients with $\mathrm{AD}$, suggesting that keratinocyte-generated chemokines are key mediators in the drawing of inflammatory lymphocytes to the skin (9-11).

Interferon (IFN)- $\gamma$, one of the multifunctional cytokines that have antiviral, anti-tumor, and immunomodulatory effects, is produced predominantly in T cells and natural killer (NK) cells (12). Upon binding to IFN- $\gamma$, the IFN- $\gamma$ receptors (IFN- $\gamma \mathrm{R} 1$ and IFN- $\gamma \mathrm{R} 2$ ) rapidly associate with Janus tyrosine kinases (JAK) 1 and JAK2. JAK1 and JAK2 phosphorylate with one another and then subsequently phosphorylate the IFN- $\gamma$ receptor, forming a docking moiety for the cytoplasmic transcription factor named signal transducer and activator of transcription (STAT) 1, a member of the STAT protein family $(13,14)$. STAT1 phosphorylation plays a critical role in the IFN-mediated innate immunity to microbial infection, especially inflammatory responses $(15,16)$. IFN- $\gamma$ also stimulates the activation of p38, extracellular signal regulated kinase 1/2 (ERK1/2), and nuclear factor kappa-light-chain-enhancer of activated $\mathrm{B}$ cells $(\mathrm{NF}-\kappa \mathrm{B})(17,18)$.

C. camphora (known as camphor tree) has glossy and waxy leaves and grows in the southern part of Jeju Island in Korea. For a long time, people in Jeju have believed that the unique odor of camphor tree drives away demons. Camphor oil that is extracted from the wood of camphor trees has been used traditionally for the relief of pain and inflammation in joints and muscles for many years (19). Other volatile oil variants (linalool, 1,8-cineole, nerolidol, safrole, and borneol) distilled from camphor trees exhibit the antifungal or molluscicidal activities (20-22). In a previous study, we reported the anti-oxidative and anti-inflammatory effects of $C$. camphora leaves in the cellular levels (23). There are few studies on the other chemical constituents of C. camphora. Therefore, in this study, the pharmacological effects of $C$. camphora on the cellular and animal allergic inflammatory events were investigated to determine its therapeutic potential for AD.

\section{MATERIALS AND METHODS}

Reagents. C. camphora leaves extract $(80 \% \mathrm{EtOH}$ extract, CCex) was provided from Jeju Biodiversity Research Institute (JBRI-10135). Human interferon- $\gamma$ (hIFN- $\gamma$ : recombinant E. coli) was purchased from Gibco (Grand Island, NY, USA), and MDC enzyme linked immunosorbent assay (ELISA) duoset kit was obtained from R\&D system (St. Louis, MO, USA). Anti-STAT1 antibody was purchased from Santa Cruz Biotechnology (Santa Cruz, CA, USA). Anti-phospho-STAT1 antibody was purchased from Cell signaling (Beverly, MA, USA), and anti- $\beta$-actin antibody, Epigallocatechingallate (EGCG) was obtained from Sigma Chemical Co (St. Louis, MO, USA). Dinitrochlorobenzene (DNCB) was purchased from Tokyo Kasei Kogyo (Tokyo, Japan). All other chemicals and reagents were of reagent grade.

Experimental animals. BALB/c mice (female, 7weeks-old) were purchased from Orient Bio (Orient Bio Inc., Seongnam, Korea) and maintained under pathogenfree conditions in the animal facility of Jeju National University. All animal experiments were approved by the Jeju National University Animal Care and Use Committee.

DNCB application to induce AD. Mice were divided into four groups ( $n=8$ per group): saline (normal), $\mathrm{AD}$ (induction-only), $\mathrm{AD}+$ Hydrocort cream, and $\mathrm{AD}+\mathrm{CCex}$. Mice were sensitized by applying 1\% 2,4-dinitrochlorobenzene (DNCB) or vehicle on their abdomen as the first sensitization (day-7). On day 0 , mice were challenged again by applying $0.3 \%$ DNCB to the ears on every other day for up to 30 days. Starting on day 12, the mice were treated with hydrocort cream (Green Cross, Yongin, Korea) containing $2 \mathrm{mg} / \mathrm{g}$ hydrocortisone valerate and CCex (10 and $100 \mathrm{mg} / \mathrm{kg})$ on their ears every other day. The mice were sacrificed on day 31 .

Cell culture and cell viability. Human adult low-calcium high-temperature ( $\mathrm{HaCaT}$ ) keratinocyte was obtained from the Amore Pacific Company (Gyeonggi, Korea). The cells were cultured in RPMI 1640 medium supplemented with $10 \%$ fetal bovine serum (FBS) and $100 \mathrm{U} / \mathrm{mL}$ penicillin-streptomycin. The cells were maintained at $37^{\circ} \mathrm{C}$ in an incubator with a humidified atmosphere of $5 \% \mathrm{CO}_{2}$. Cell viability was determined using an EZ-cytox-enhanced cell viability assay kit (itsBIO, Seoul, Korea) following the manufacturer's protocol. Briefly, cells were seeded into the wells of a 96-well plate and treated with IFN- $\gamma$ $(10 \mathrm{ng} / \mathrm{mL})$ in the absence or presence of CCex for $24 \mathrm{hr}$. A solution of 2-(4-iodophenyl)-3-(4-nitrophenyl)-5-(2,4disulfophenyl)- $2 H$ tetrazolium (WST) was added to each well and incubated for $1 \mathrm{hr}$ in an incubator. Then, the absorbance of each well was measured at $450 \mathrm{~nm}$ with a VersaMax ELISA microplate reader (Molecular Devices Inc., Sunnyvale, CA, USA).

Enzyme-linked immunosorbent assays (ELISA). Secretion of the MDC protein into the supernatant of cultured cells was measured by using an ELISA kit (R\&D 
Systems Inc., Minneapolis, MN, USA) according to the manufacturer's instructions. Briefly, HaCaT cells were stimulated with IFN- $\gamma$ in the presence of CCex for $24 \mathrm{hr}$. The cell culture medium was transferred to a 96-well culture plate coated with MDC antibody and treated according to the manufacturer's (R\&D Systems) instructions. Absorbance at $450 \mathrm{~nm}$ was recorded by using the VersaMax ELISA microplate reader (Molecular Devices, Sunnyvale, CA, USA).

Western blot analysis. The cells were washed twice with ice-phosphate buffered saline (PBS). The cells were disrupted in the lysis buffer (iNtRON Biotechnology, Gyeonggi, Korea) for $30 \mathrm{~min}$ on ice. Protein of the supernatants was quantified via the Bradford assay (Bio-rad, Herculers, CA, USA). Aliquots of the lysates were separated on a NuPAGE $4-12 \%$ bis-Tris gel (Invitrogen, Carlsbad, CA, USA). The proteins were transferred onto a polyvinylidene difluoride (PVDF) membrane using an iBlot gel transfer device (Invitrogen). Then membranes were blocked with $5 \%$ non-fat skim milk solution diluted Tween 20-tris buffered saline (TTBS), and the membranes were incubated with primary antibodies diluted in $1 \%$ bovine serum albumin (BSA)-TTBS buffer at $4^{\circ} \mathrm{C}$ overnight. After washing, the membrane was incubated with secondary HRP-linked anti-rabbit or anti-mouse $\mathrm{IgG}$ respectively for $90 \mathrm{~min}$ at room temperature. After washing again, immune active proteins were determined with WEST-ZOL (plus) western blot detection system (iNtRON Biotechnology) according to the manufacturer's instructions.

Macroscopic edema and histology. In the experimental AD mouse model, DNCB stimulation elicited ear edema, and ear thickness was measured using a Digital Thickness Gauge (Mitutoyo, Kawasaki, Japan). Ear tissues were fixed in $10 \%$ formalin, and then embedded in paraffin. Paraffin sections ( $3 \mu \mathrm{M}$ each) were stained with by hematoxylin and eosin (H\&E).

Statistical analysis. Quantity One version 4.2.1 (Bio$\mathrm{Rad}$ ) and Image-Pro plus version 4.5 software (Media Cybernetics, Silver Spring, MD, USA) were used to transform images into numerical values. Student's $t$-test and two-way analysis of variance were used to determine the statistical significance of differences between experimental and control groups. Data are shown as mean \pm standard deviation. $P$ values less than 0.05 were considered statistically significant.

\section{RESULTS}

Effect of CCex on the MDC production in the IFN- $\gamma$ stimulated HaCaT keratinocytes. We first examined the cell cytotoxicity of CCex against HaCaT cells. The cells were treated with different concentrations of CCex $(12.5,25,50$, and $100 \mu \mathrm{g} / \mathrm{mL})$ for $24 \mathrm{hr}$. Cell viability was
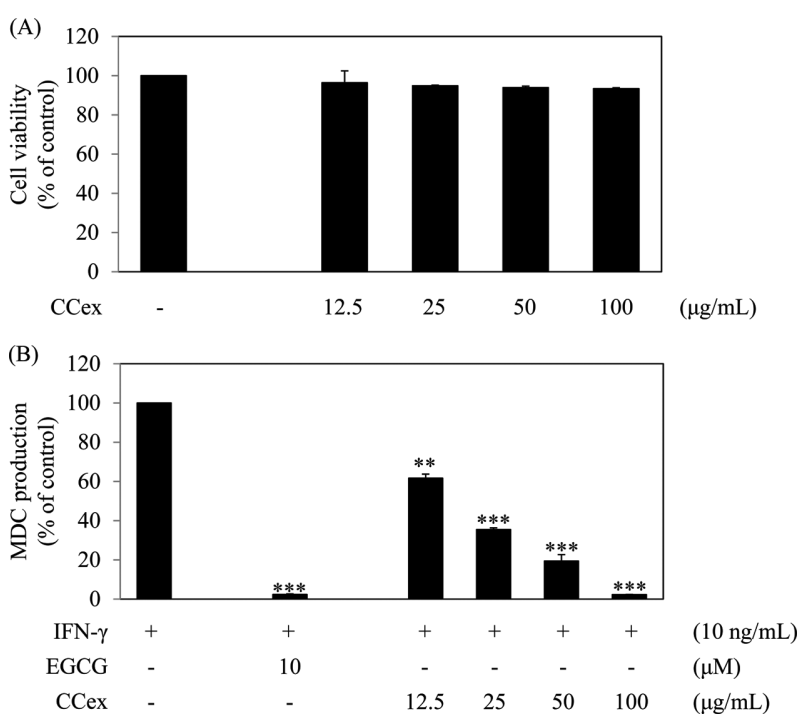

Fig. 1. Effect of CCex on the MDC production in the IFN- $\gamma$ stimulated HaCaT keratinocytes. (A) Cells $\left(1.5 \times 10^{5}\right.$ cells $\left./ \mathrm{mL}\right)$ were pre-incubated for $18 \mathrm{hr}$, and then treated with IFN- $\gamma(10 \mathrm{ng} /$ $\mathrm{mL})$ in the presence or absence of CCex for $24 \mathrm{hr}(12.5-100 \mu \mathrm{g} /$ $\mathrm{mL}$ ). Cell viability was determined by the WST assay. (B) Cells $\left(1.5 \times 10^{5}\right.$ cells $\left./ \mathrm{mL}\right)$ were pre-incubated for $18 \mathrm{hr}$ and then treated with CCex $(12.5-100 \mu \mathrm{g} / \mathrm{mL})$ in the presence of IFN- $\gamma(10 \mathrm{ng} /$ $\mathrm{mL}$ ) for $24 \mathrm{hr}$. The amounts of MDC were measured from the culture supernatants by ELISA. EGCG was used as a positive control. Data are the mean \pm SD of three independent experiments. ${ }^{* *} p<0.01$ and ${ }^{* * *} p<0.001$ vs. CCex-untreated cells in the presence of IFN- $\gamma$.

determined using the EZ-cytox-enhanced cell viability assay kit (itsBIO). As shown in Fig. 1A CCex did not exhibit cytotoxicity to HaCaT keratinocytes at the assayed concentrations. Then, we evaluated the inhibitory effect of CCex on inflammatory chemokine (MDC) production in IFN- $\gamma(10 \mathrm{ng} / \mathrm{mL})$-stimulated HaCaT keratinocytes. Results showed that CCex suppressed the production of MDC by IFN- $\gamma$ in a concentration-dependent manner (Fig. 1B).

Effect of CCex on the phosphorylation of STAT1 in IFN- $\gamma$-stimulated HaCaT keratinocytes. STAT1 protein is a crucial and specific regulator of IFN- $\gamma$-induced signals that control the transcription of target genes, including MDC $(13,14,24,25)$. Therefore, we assayed the effect of CCex on the activation of STAT1 in IFN- $\gamma$ treated HaCaT keratinocytes, and detected a high level of phosphorylated STAT1 15 min after cytokine treatment. The pretreatment of cells with CCex for 120 min suppressed STAT1 (tyrosine 701 and serine 727) phosphorylation in a dose dependent manner (Fig. 2).

Effect of CCex on the phosphorylation of ERK1/2 in IFN- $\gamma$-stimulated HaCaT keratinocyte. The mitogenactivated protein kinase (MAPK)s pathway is reportedly 
(A)
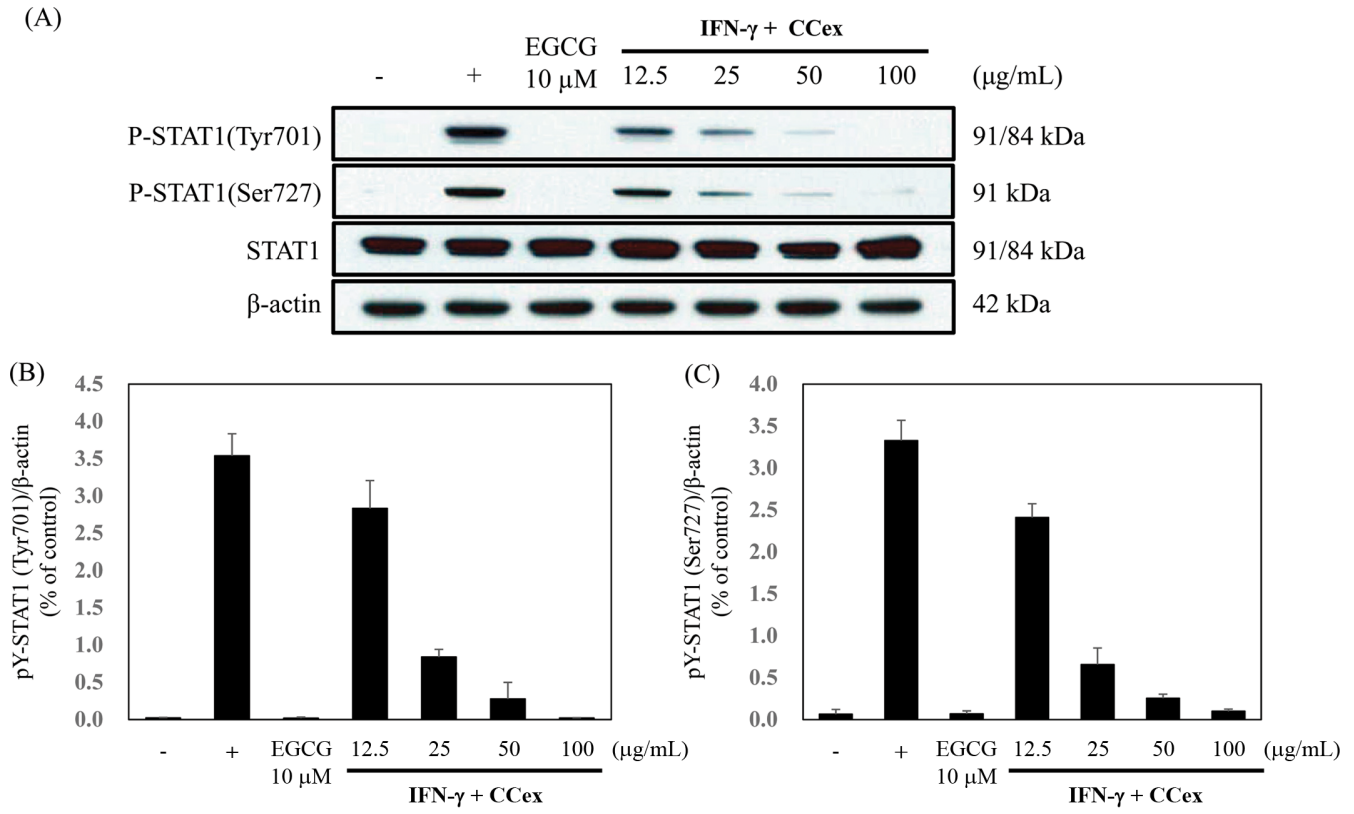

Fig. 2. Effect of CCex on the phosphorylation of STAT1 in IFN- $\gamma$-stimulated HaCaT keratinocytes. (A) Cells $\left(5.0 \times 10^{5}\right.$ cells $\left./ \mathrm{mL}\right)$ were pretreated with CCex $(12.5-100 \mu \mathrm{g} / \mathrm{mL})$ for $120 \mathrm{~min}$ and stimulated with IFN- $\gamma(10 \mathrm{ng} / \mathrm{mL})$ for $120 \mathrm{~min}$. The levels of phosphorylated STAT1 (Tyr701, Ser727) were assessed by Western blotting from whole cell lysates. (B, C) Data represent the density ration of STAT 1 (Tyr701) and STAT1 (Ser727) phosphorylation in IFN- $\gamma$-stimulated HaCaT keratinocytes. EGCG was used as a positive control.

involved in the production of inflammatory chemokines, and IFN- $\gamma$ activates the receptor-associated MAPKs depending on the cell type $(17,18)$. Thus, we investigated the involvement of these signaling kinases in IFN- $\gamma$-induced
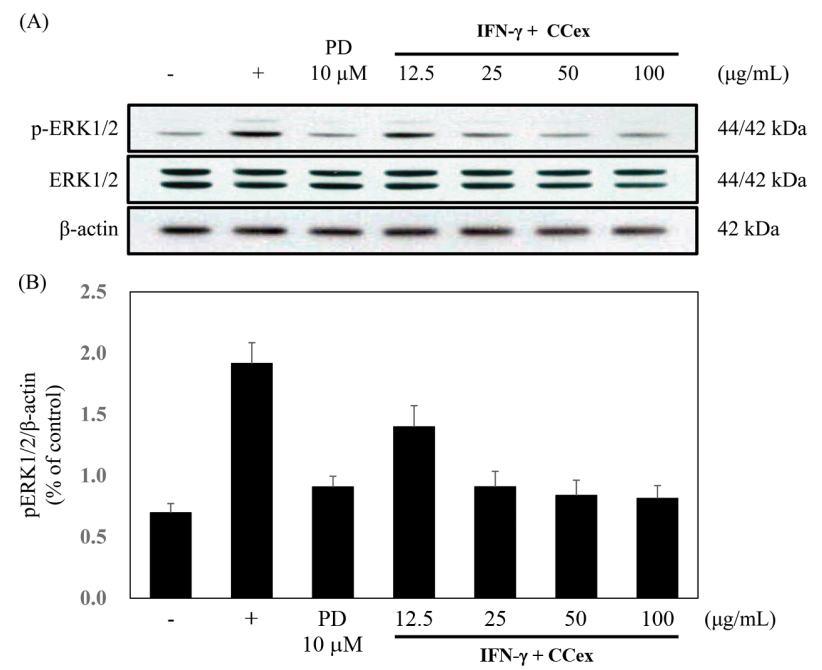

Fig. 3. Effect of CCex on the phosphorylation of ERK $1 / 2$ in IFN- $\gamma$-stimulated HaCaT keratinocyte. (A) Cells $\left(5.0 \times 10^{5}\right.$ cells/ $\mathrm{mL}$ ) were pretreated with CCex $(12.5-100 \mu \mathrm{g} / \mathrm{mL})$ for $120 \mathrm{~min}$ and stimulated with IFN- $\gamma(10 \mathrm{ng} / \mathrm{mL})$ for $5 \mathrm{~min}$. The levels of phosphorylated ERK1/2 were assessed by Western blotting from whole cell lysates. (B) Data represent the density ratio of ERK1/ 2 phosphorylation in IFN- $\gamma$-stimulated $\mathrm{HaCaT}$ keratinocytes. PD98059 (ERK1/2 inhibitor) was used as a positive control.
MDC production in $\mathrm{HaCaT}$ cells. We first determined the time dependent activation of three MAPKs (ERK1/2, cjun N-terminal kinase (JNK), and p38) after IFN- $\gamma$ treatment. IFN- $\gamma$ induced the phosphorylation of ERK1/2 at 5 min, whereas there was no effect on the phosphorylation of JNK and p38 (data not shown). Then we examined the inhibitory effect of CCex on ERK1/2 activation in IFN- $\gamma$ stimulated HaCaT cells. As shown in Fig. 3, CCex suppressed the ERK1/2 phosphorylation at the concentrations of 25,50 , and $100 \mu \mathrm{g} / \mathrm{mL}$.

CCex decreases serum IgE level. To induce AD experimentally, mice were subjected to initial sensitization with $1 \%$ DNCB on the abdomen. They were then resensitized by applying $0.3 \%$ DNCB to the ears every other day for up to 31 days. Starting on day 12, the mice were treated with hydrocortisone cream and CCex (10 and $100 \mathrm{mg} / \mathrm{kg}$ ) on the ears every other day. All mice were sacrificed on day 31 (Fig. 4A). IgE is a crucial therapeutic target for $\mathrm{AD}$, as it is the major activator of mast cells, which release histamine, tryptase, and cytokine (4). Therefore, we measured serum IgE levels in mice with dermatitis by using ELISA method. The CCex-treated group showed significantly decreased levels of $\operatorname{IgE}(p<0.05)$ compared with the induction group (Fig. 4B).

\section{CCex alleviates the development of experimental} $\boldsymbol{A D}$. The skin lesions associated with AD are characterized by infiltration of various inflammatory cells $(26,27)$. 
(A)

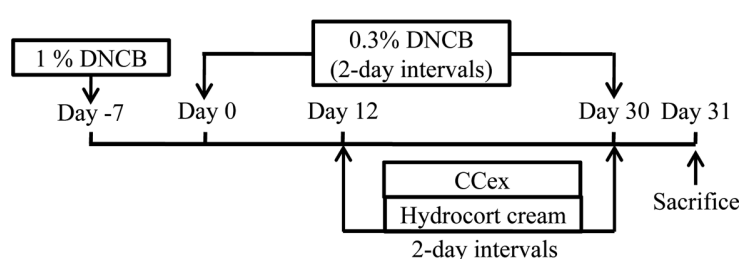

(B)

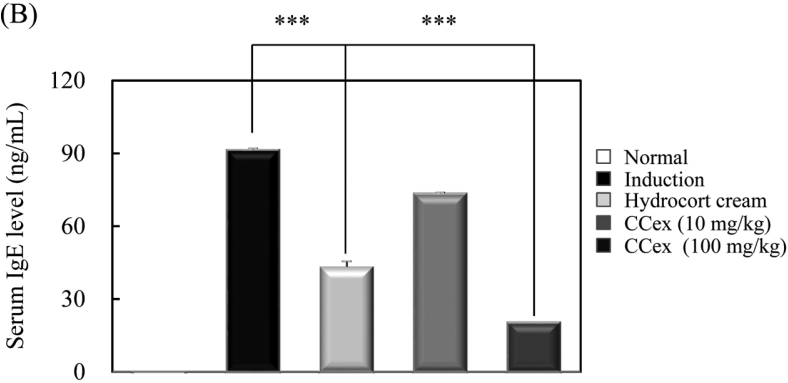

Fig. 4. CCex decreases serum lgE level. (A) Mice were sensitized by applying $1 \%$ DNCB or vehicle on their abdomen as the first sensitization (day-7). On day 0 , mice were challenged again by applying $0.3 \%$ DNCB to the ears on every other day for up to 30 days. Starting on day 12 , the mice were treated with hydrocort cream and CCex (10 and $100 \mathrm{mg} / \mathrm{kg}$ ) on their ears every other day. The mice were sacrificed on day 31. (B) After sacrifice, the IgE in mouse serum was measured by ELISA. Values represent the mean $\pm S D$. ${ }^{* * *} p<0.001$ compared to mice stimulated with DNCB alone (induction group).
Therefore, we determined whether CCex treatment alleviates the inflammatory cell infiltration in the ears of $\mathrm{AD}$ mice. We also tested skin swelling as a measure of $\mathrm{AD}$ progression. We found that cutaneous edema in CCex treated mice was reduced on day $29(p<0.05)$ compared with that in the induction-only mice (Fig. 5A, 5B). We next examined the effect of CCex on the infiltration of inflammatory cells by H\&E staining of ear tissue sections. Epidermal thickness and the degree of inflammatory cell infiltration were significantly lower in the CCextreated group than in the induction group (Fig. 5C). Lymph node (LN)s play a crucial role in cell-mediated immunity by regulating the activity of $\mathrm{T}$ and $\mathrm{B}$ cells (28). Therefore, we examined the morphologic changes in the LNs of AD mice. The LNs of mice in the induction-only group were quite swollen, whereas those in CCex-treated mice were smaller (Fig. 5D).

\section{DISCUSSION}

MDC/CCL22 is a key mediator in drawing inflammatory lymphocytes to the skin, and resulting in skin inflammation (9-11). In the present study, C. camphora leaves (80\% EtOH extract, CCex) potentially inhibited MDC production in IFN- $\gamma$-stimulated $\mathrm{HaCaT}$ keratinocytes. CCex did not show any effect on the production of inter-

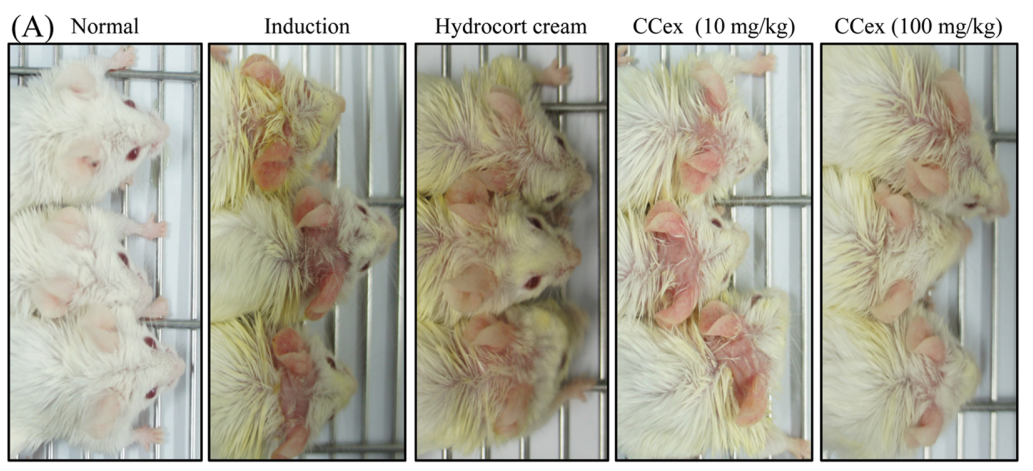

(C)
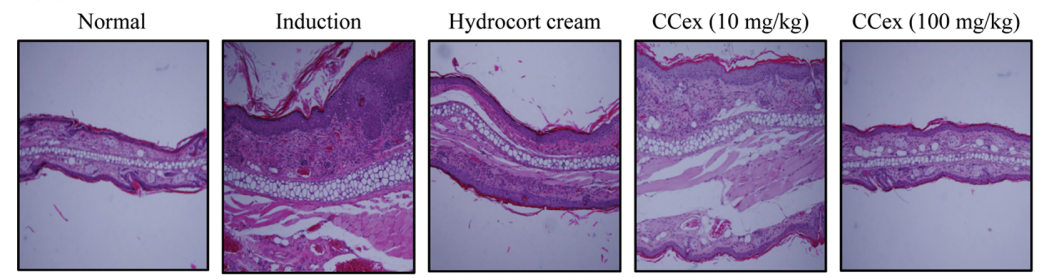

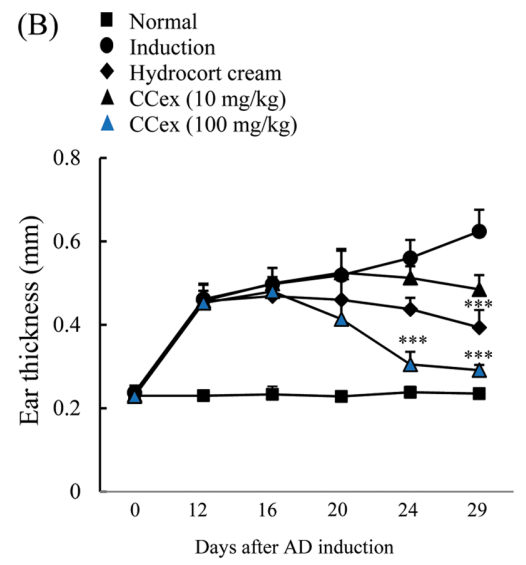

(D)

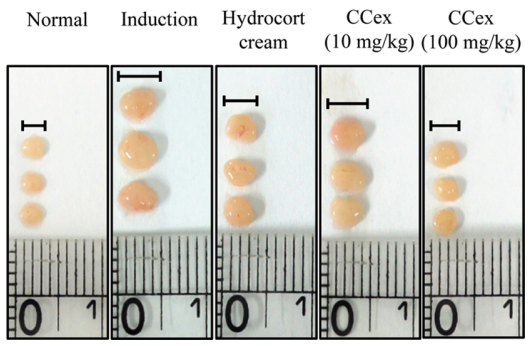

Fig. 5. CCex alleviates the development of experimental AD. (A) Photos of the ears. (B) Ear thickness at indicated days. (C) Paraffinembeded sections of ear tissue stained with hematoxylin and eosin. (D) Photos of the lymph nodes (LNs). Values represent the mean \pm SD. ${ }^{* * *} p<0.001$ compared to mice stimulated with DNCB alone (induction group). 
leukin (IL)-6 and tumor necrosis factor (TNF)- $\alpha$, major inflammatory cytokines in LPS-induced macrophages (data not shown). These results suggest that CCex has effective components acting on skin keratinocytes. Hence, we assayed the inhibitory effects of four available components (camphor, cineole, nerolidol and linalool) of C. camphora on MDC production in IFN- $\gamma$ stimulated $\mathrm{HaCaT}$ keratinocytes. All tested components did not show any effect on the MDC production (data not shown).

To identify the mechanism by which CCex inhibits MDC production, we investigated the phosphorylation of intracellular signaling molecules related to immune responses in skin cells. The JAK-STAT signal pathway is induced by IFN- $\gamma$, an important mediator of immunity and inflammation. Hald et al reported that Tyr701 and Ser727 expression of STAT1 is increased in psoriatic skin lesion (29). Furthermore, IFN- $\gamma$ activates the MEK/ERK signal pathway $(30,31)$, and a previous study suggested that ERK1/2 is related to STAT1 activation induced by IFN- $\gamma$. In particular, Ser727 phosphorylation of STAT1 was attributed to the inhibition of ERK (32). CCex suppressed the phosphorylation of STAT1 (Tyrosine 701 and Serine 727 residues) in a dose dependent manner. CCex $(12.5-100 \mu \mathrm{g} / \mathrm{mL})$ also suppressed the phosphorylation of ERK1/2, a central signaling molecule in the inflammation process. EGCG, an active ingredient of green tea, is known to be a potent STAT1 inhibitor (33). In the present study, EGCG $(10 \mu \mathrm{M})$ potentially inhibited STAT1 (Tyr701 and Ser727 residues) phosphorylation after $2 \mathrm{hr}$ treatment and then MDC production after $24 \mathrm{hr}$ treatment. These results suggest that CCex inhibits MDC/CCL22 production via the down-regulation of STAT1 and ERK1/2 pathways in skin inflammation lesions.

While a significant number of natural products are effective at the cellular level, they are often not effective when applied to animal experiments. To study the in vivo effects of CCex on $\mathrm{AD}$, we induced experimental $\mathrm{AD}$ in mice by applying of DNCB. IgE is a major therapeutic target for $\mathrm{AD}$, and $\mathrm{IgE}$ levels are related to the severity of $\mathrm{AD}$ and associated with abnormal skin barrier $(4,34)$. In this study, the CCex-treated group showed significantly decreased levels of serum $\operatorname{IgE}(p<0.001)$ compared with the induction group. The cutaneous edema in CCex-treated mice was reduced on day $29(p<0.001)$ compared with that observed in the induction mice. Furthermore, epidermal thickness and the degree of inflammatory cell infiltration were significantly lower in the CCex-treated group than in the induction group. LNs are located throughout the body and are related to site initiated pathogenic antigens. LNs also act as a secondary lymphoid organ, so that the rare antigen-specific immune cells can increase their contact with their cognate antigen $(35,36)$. Our results showed that the LNs in mice in the induction group were quite swollen, whereas those in CCex-treated mice were smaller.
Hence, CCex alleviated the pathologic symptoms in $\mathrm{AD}$ mice.

In conclusion, $\mathrm{CCex}$ inhibited the production of MDC, a principal chemokine in skin inflammation via down-regulation of STAT1 and ERK1/2 signaling and improved several symptoms (ear edema, serum IgE levels, histological change, lymph node size) in mice AD. These results suggest that C. camphora leaves help in the treatment of allergic inflammation such as $\mathrm{AD}$.

\section{ACKNOWLEDGMENTS}

This work was supported by the research grant of Jeju National University in 2017.

\section{CONFLICT OF INTEREST}

None declared.

Received November 5, 2018; Revised December 24, 2018; Accepted January 16, 2019

\section{REFERENCES}

1. Leung, D.Y., Boguniewicz, M., Howell, M.D., Nomura, I. and Hamid, Q.A. (2004) New insights into atopic dermatitis. J. Clin. Invest., 113, 651-657.

2. Li, C., Lasse, S., Lee, P., Nakasaki, M., Chen, S.-W., Yamasaki, K., Gallo, R.L. and Jamora, C. (2010) Development of atopic dermatitis-like skin disease from the chronic loss of epidermal caspase-8. Proc. Natl. Acad. Sci. U.S.A., 107, 22249-22254.

3. Nystad, W., Røysamb, E., Magnus, P., Tambs, K. and Harris, J.R. (2005) A comparison of genetic and environmental variance structures for asthma, hay fever and eczema with symptoms of the same diseases: a study of Norwegian twins. Int. J. Epidemiol., 34, 1302-1309.

4. Levin, T.A., Ownby, D.R., Smith, P.H., Peterson, E.L., Williams, L.K., Ford, J., Young, P. and Johnson, C.C. (2006) Relationship between extremely low total serum IgE levels and rhinosinusitis. Ann. Allergy Asthma Immunol., 97, 650-652.

5. Yoshie, O., Imai, T. and Nomiyama, H. (2001) Chemokines in immunity. Adv. Immunol., 78, 57-110.

6. Bäumer, W., Seegers, U., Braun, M., Tschernig, T. and Kietzmann, M. (2004) TARC and RANTES, but not CTACK, are induced in two models of allergic contact dermatitis. Effects of cilomilast and diflorasone diacetate on Tcell-attracting chemokines. Br. J. Dermatol., 151, 823-830.

7. Yamashita, U. and Kuroda, E. (2002) Regulation of macrophage-derived chemokine (MDC/CCL22) production. Crit. Rev. Immunol., 22, 105-114.

8. Saeki, H. and Tamaki, K. (2006) Thymus and activation regulated chemokine (TARC)/CCL17 and skin diseases. J. Dermatol. Sci., 43, 75-84.

9. Shimada, Y., Takehara, K. and Sato, S. (2004) Both Th2 and Th1 chemokines (TARC/CCL17, MDC/CCL22, and Mig/ CXCL9) are elevated in sera from patients with atopic der- 
matitis. J. Dermatol. Sci., 34, 201-208.

10. Jahnz-Rozyk, K., Targowski, T., Paluchowska, E., Owczarek, W. and Kucharczyk, A. (2005) Serum thymus and activation-regulated chemokine, macrophage-derived chemokine and eotaxin as markers of severity of atopic dermatitis. Allergy, 60, 685-688.

11. Maeda, S., Fujiwara, S., Omori, K., Kawano, K., Kurata, K., Masuda, K., Ohno, K. and Tsujimoto, H. (2002) Lesional expression of thymus and activation-regulated chemokine in canine atopic dermatitis. Vet. Immunol. Immunopathol., 88, 79-87.

12. Farrar, M.A. and Schreiber, R.D. (1993) The molecular cell biology of interferon-gamma and its receptor. Annu. Rev. Immunol., 11, 571-611.

13. Best, S.M., Morris, K.L., Shannon, J.G., Robertson, S.J., Mitzel, D.N., Park, G.S., Boer, E., Wolfinbarger, J.B. and Bloom, M.E. (2005) Inhibition of interferon-stimulated JAK-STAT signaling by a tick-borne flavivirus and identification of NS5 as an interferon antagonist. J. Virol., 79, 12828-12839.

14. Ivashkiv, L.B. and Hu, X. (2004) Signaling by stats. Arthritis Res. Ther, 6, 159-168.

15. Ju, S.M., Song, H.Y., Lee, S.J., Seo, W.Y., Sin, D.H., Goh, A.R., Kang, Y.-H., Kang, I.-J., Won, M.-H. and Yi, J.-S. (2009) Suppression of thymus-and activation-regulated chemokine (TARC/CCL17) production by 1, 2, 3, 4, 6-penta-O-galloyl$\beta$-d-glucose via blockade of NF- $\mathrm{KB}$ and STAT1 activation in the HaCaT cells. Biochem. Biophys. Res. Commun., 387, 115-120.

16. Kang, G.-J., Kang, N.-J., Han, S.-C., Koo, D.-H., Kang, H.-K., Yoo, B.-S. and Yoo, E.-S. (2012) The chloroform fraction of carpinus tschonoskii leaves inhibits the production of inflammatory mediators in $\mathrm{HaCaT}$ keratinocytes and RAW264. 7 macrophages. Toxicol. Res., 28, 255-262.

17. Pearson, G., Robinson, F., Beers Gibson, T., Xu, B.-e., Karandikar, M., Berman, K. and Cobb, M.H. (2001) Mitogen-activated protein (MAP) kinase pathways: regulation and physiological functions. Endocr. Rev., 22, 153-183.

18. Madonna, S., Scarponi, C., De Pità, O. and Albanesi, C. (2008) Suppressor of cytokine signaling 1 inhibits IFN- $\gamma$ inflammatory signaling in human keratinocytes by sustaining ERK1/2 activation. FASEB J., 22, 3287-3297.

19. Hamidpour, R., Hamidpour, S., Hamidpour, M. and Shahlari, M. (2013) Camphor (Cinnamomum camphora), a traditional remedy with the history of treating several diseases. Int. J. Case Rep. Imag., 4, 86-89.

20. Guo, S., Geng, Z., Zhang, W., Liang, J., Wang, C., Deng, Z. and Du, S. (2016) The chemical composition of essential oils from Cinnamomum camphora and their insecticidal activity against the stored product pests. Int. J. Mol. Sci., 17, 1836.

21. Pragadheesh, V., Saroj, A., Yadav, A., Chanotiya, C., Alam, M. and Samad, A. (2013) Chemical characterization and antifungal activity of Cinnamomum camphora essential oil. Ind. Crops Prod., 49, 628-633.

22. Yang, F., Long, E., Wen, J., Cao, L., Zhu, C., Hu, H., Ruan, Y., Okanurak, K., Hu, H. and Wei, X. (2014) Linalool, derived from Cinnamomum camphora (L.) Presl leaf extracts, possesses molluscicidal activity against Oncomelania hupensis and inhibits infection of Schistosoma japonicum. Parasit. Vectors, 7, 407.
23. Lee, H.-J., Hyun, E.-A., Yoon, W.-J., Kim, B.-H., Rhee, M.-H., Kang, H.-K., Cho, J.-Y. and Yoo, E.-S. (2006) In vitro anti-inflammatory and anti-oxidative effects of Cinnamomum camphora extracts. J. Ethnopharmacol., 103, 208-216.

24. Kang, G.-J., Lee, H.-J., Yoon, W.-J., Yang, E.-J., Park, S.-S., Kang, H.-K., Park, M.-H. and Yoo, E.-S. (2008) Prunus yedoensis inhibits the inflammatory chemokines, MDC and TARC, by regulating the STAT1-signaling pathway in IFN$\gamma$-stimulated HaCaT human keratinocytes. Biomol. Ther. (Seoul), 16, 394-402.

25. Rauch, I., Müller, M. and Decker, T. (2013) The regulation of inflammation by interferons and their STATs. JAKSTAT, 2, e23820.

26. Kim, J., Lee, J., Shin, S., Cho, A. and Heo, Y. (2018) Molecular mechanism of atopic dermatitis induction following sensitization and challenge with 2,4-dinitrochlorobenzene in mouse skin tissue. Toxicol. Res., 34, 7-12.

27. de Vries, I.J.M., Langeveld-Wildschut, E.G., van Reijsen, F.C., Bihari, I.C., Bruijnzeel-Koomen, C.A. and Thepen, T. (1997) Nonspecific T-cell homing during inflammation in atopic dermatitis: expression of cutaneous lymphocyte-associated antigen and integrin $\alpha E \beta 7$ on skin-infiltrating $T$ cells. J. Allergy Clin. Immunol., 100, 694-701.

28. Debes, G.F., Bonhagen, K., Wolff, T., Kretschmer, U., Krautwald, S., Kamradt, T. and Hamann, A. (2004) CC chemokine receptor 7 expression by effector/memory CD4+ T cells depends on antigen specificity and tissue localization during influenza A virus infection. J. Virol., 78, 7528-7535.

29. Hald, A., Andrés, R., Salskov-Iversen, M., Kjellerup, R., Iversen, L. and Johansen, C. (2013) STAT1 expression and activation is increased in lesional psoriatic skin. Br. J. Dermatol., 168, 302-310.

30. Platanias, L.C. (2005) Mechanisms of type-I-and type-II-interferon-mediated signalling. Nat. Rev. Immunol., 5, 375-386.

31. Roy, S.K., Hu, J., Meng, Q., Xia, Y., Shapiro, P.S., Reddy, S.P., Platanias, L.C., Lindner, D.J., Johnson, P.F. and Pritchard, C. (2002) MEKK1 plays a critical role in activating the transcription factor $\mathrm{C} / \mathrm{EBP}-\beta$-dependent gene expression in response to IFN- $\gamma$. Proc. Natl. Acad. Sci. U.S.A., 99, 7945-7950.

32. Li, N., McLaren, J.E., Michael, D.R., Clement, M., Fielding, C.A. and Ramji, D.P. (2010) ERK is integral to the IFN$\gamma$-mediated activation of STAT1, the expression of key genes implicated in atherosclerosis, and the uptake of modified lipoproteins by human macrophages. J. Immunol., 185, 3041-3048.

33. Menegazzi, M., Tedeschi, E., Dussin, D., de Prati, A.C., Cavalieri, E., Mariotto, S. and Suzuki, H. (2001) Anti-interferon $\gamma$ action of epigallocatechin-3-gallate mediated by specific inhibition of STAT1 activation. FASEB J., 15, 1309-1311.

34. Liu, F.-T., Goodarzi, H. and Chen, H.-Y. (2011) IgE, mast cells, and eosinophils in atopic dermatitis. Clin. Rev. Allergy Immunol., 41, 298-310.

35. Koning, J.J. and Mebius, R.E. (2012) Interdependence of stromal and immune cells for lymph node function. Trends Immunol., 33, 264-270.

36. Buettner, M. and Bode, U. (2012) Lymph node dissectionunderstanding the immunological function of lymph nodes. Clin. Exp. Immunol., 169, 205-212. 